\title{
Facial reconstruction: Validation of the Tedeschi-Oliveira method for estimating the pronasale point in Brazilians
}

\begin{abstract}
Raíssa Ananda Paim STRAPASSON(a,b)
\end{abstract}
Rodolfo Francisco Haltenhoff MELANI(b) (iD

(a) Universidade Federal do Rio Grande do Sul - UFRGS, School of Dentistry, Department of Preventive and Social Dentistry, Porto Alegre, RS, Brazil.

(b) Universidade de São Paulo - USP, School of Dentistry, Department of Social Dentistry, São Paulo, SP, Brazil.
Declaration of Interests: The authors certify that they have no commercial or associative interest that represents a conflict of interest in connection with the manuscript.

\section{Corresponding Author:}

Raíssa Ananda Paim Strapasson

E-mail: raissa.ananda@gmail.com

https://doi.org/10.1590/1807-3107bor-2020.vol34.0091

Submitted: January 1, 2020

Accepted for publication: May 28, 2020

Last revision: June 16, 2020
Abstract: Forensic facial reconstruction aids in the process of human identification by facial recognition. The nose plays an important role in this process; however, its soft tissues wither away during cadaveric decomposition. There are few studies in the area of facial recognition of the Brazilian population, especially concerning Brazilian nasal prediction guides. This study aimed to test the hypothesis that the angle formed by the tangents drawn from the rhinion and prosthion points (nose tip) is equal to $90^{\circ}$, as proposed by the pioneer study by Tedeschi-Oliveira et al. (2016). It is important to highlight that this is the only method to date developed to predict the nasal tip in Brazilians, and has not yet been tested in other populations. Images of computed tomography scans of 228 individuals (171 females and 57 males) were screened according to the same criteria used by the authors of the primary study. The images were analyzed using the Horos ${ }^{\circledR}$ program, version 1.1 .7 - 64 bit. The mean angle studied was about $90^{\circ}$, and any difference between this mean and the real angle measured did not significantly compromise the accuracy of the nose tip location. The findings tested in the present study corroborate the hypothesis investigated by Tedeschi-Oliveira et. al. Therefore, we suggest that the method be used in forensic practice to estimate nose tips in Brazilians.

Keywords: Forensic Sciences; Forensic Anthropology; Facial Recognition; Nose.

\section{Introduction}

Forensic facial reconstruction (or forensic facial approximation) is an auxiliary method that can be used to allow facial recognition in human identification processes, when the primary methods cannot be applied. ${ }^{1}$ Small changes in facial structures may alter the final appearance and characterization of the face, and thus compromise recognition. ${ }^{1}$

It is known that the facial shape, as well as the morphology of facial features, depends on skull morphology, and hard (cartilaginous) and soft (muscle and adipose) ${ }^{1}$ tissues partly influenced by an individual's sex, age and ancestry. ${ }^{1}$

The final characterization of the face is also influenced by the individual traits not related to bone formation, and congenital or predictable genetic manifestations, such as scars, wrinkles, birthmarks, 
and others. The influence of these factors on facial recognition can be minimized by conducting studies to establish accurate technical-scientific parameters to estimate the face using the elements made available by the skull. For this reason, facial soft tissues are studied according to populations, sexes and ages.

The nose is located in the center of the face, and exerts great influence on facial recognition, together with the mouth and eyes. ${ }^{1,2,3}$ As regards the influence of sex on nasal morphology, it is well established that women tend to have a smaller nasal structure than men; ${ }^{4,5,6,7}$ this dimorphism becomes evident after childhood ${ }^{4}$. Furthermore, the nose is composed mostly of tissues that suffer decay after death (cartilaginous, muscular, adipose and vascular tissues), leaving few reliable bone parameters to enable approximation. ${ }^{8,9,10,11}$ There are several studies in the literature that propose methods to acquire information on nasal approximation. ${ }^{12,13,14,15,16,17,18,19,20,21,22,23}$ Stephan et al., ${ }^{15}$ for example, developed a technique based on regression equations to quantify links between the soft and hard dimensions of the nose. Macho ${ }^{12}$ also proposed a technique based on the application of some measurements taken in the nasion-sella plane, using the regression equation to predict nasal height, length and depth. However, these methods often require complex tracing, which increases the chance of error upon reconstruction, and therefore makes them inadequate to apply in forensic practice.

In Brazil, studies on this facial recognition technique are still scarce, and the existing validated methods have been unable to make facial approximations that could be applied reliably to its population. This gap was partly filled by Tedeschi-Oliveira et al., ${ }^{24}$ who proposed a method of estimating a nasal projection from the rhinion and prosthion points, both landmarks on the bone surface. The authors believe that the junction of the tangents drawn from these points forms a vertex of approximately $90^{\circ}$, that is, the point where the tip of the nose would be located (pronasale point). It should be emphasized that their research was developed using radiographies of a Brazilian sample.
The present study aims to validate the method presented by Tedeschi-Oliveira et al. ${ }^{24}$ using a different Brazilian sample and CBCT exams.

\section{Methodology}

The present study was approved by the research ethics committee of the School of Dentistry of the University of São Paulo, registered under protocol number 2.135.168. The sample consisted of 228 conebeam CT images ( 171 females and 57 males) from the collection of the Laboratory of Image Analysis and Processing of the School of Dentistry, University of São Paulo (LAPI FO-USP). The inclusion criteria consisted of individuals of both sexes, aged $\geq 24$ years, not having been submitted to any orthognathic surgery, with no craniofacial deformities, no rehabilitated canines or upper canine tooth loss.

The samples were analyzed using the Horos ${ }^{\circledR}$ open source software program, version 1.1.7 - 64 bit (Purview, Annapolis, Maryland, USA); all the Horos ${ }^{\circledR}$ tools used in this study are public domain. The analysis was performed entirely using multiplanar reconstruction (3D MPR) visualization, and maximum intensity projection (MIP) equal to zero, in order to minimize image distortion.

The study examiner marked the following points in the median sagittal plane with the point tool (Figure 1), following the same parameters as Tedeschi-Oliveira et al.:24

a. Rhinion (rhi): located at the lower border of the nasal bone

b. Pronasale (pn): located in the soft tissue, at the most prominent point of the nose (tip of the nose), aligned with the tangent that passes through the pogonion point (pg). This point was recorded as the 'actual pn.'

c. Prosthion (pr): the lowest point of the alveolar bone crest, located between the upper central incisors.

Once the points were marked, they were joined with the angle tool to gauge the rhi-pn-pr angle. This measurement was recorded as the 'actual angle' (Figure 2). Then, the angle tool was used to position 


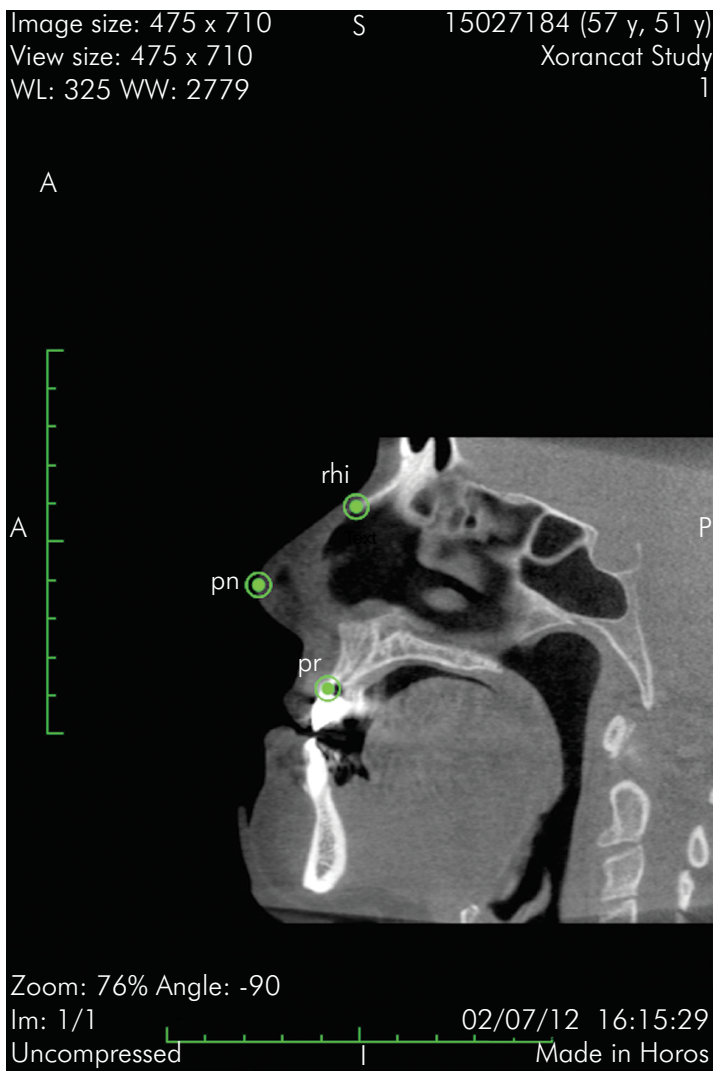

Figure 1. Sagittal window of multiplanar reconstruction with $0 \mathrm{~mm}$ MIP set, medial sagittal cut. The landmark establishes the rhi, pn and pr points.

the vertex in line with the pronasale point, until the value of the angle equaled $90^{\circ}$. This was recorded as the 'estimated angle,' and the vertex, as the 'estimated pn' (Figure 3).

The 'length' tool was used to draw a line between the actual and estimated pn points, in order to gauge the distance between these points. The distance measured was recorded as the 'actual distance.'

The estimated distance between the actual pn and the estimated pn was calculated based on the Tedeschi-Oliveira et al. ${ }^{24}$ hypothesis that each degree of difference between the actual and estimated angles corresponds to $0.31 \mathrm{~mm}$.

The statistical analysis was performed using the SPSS program (version 21). The distribution of the rhi-pn-pr angle was measured based on the mean and the range. Since the sample distribution was normal (Shapiro-Wilk), the t-test was used to check whether there was a difference between the actual and

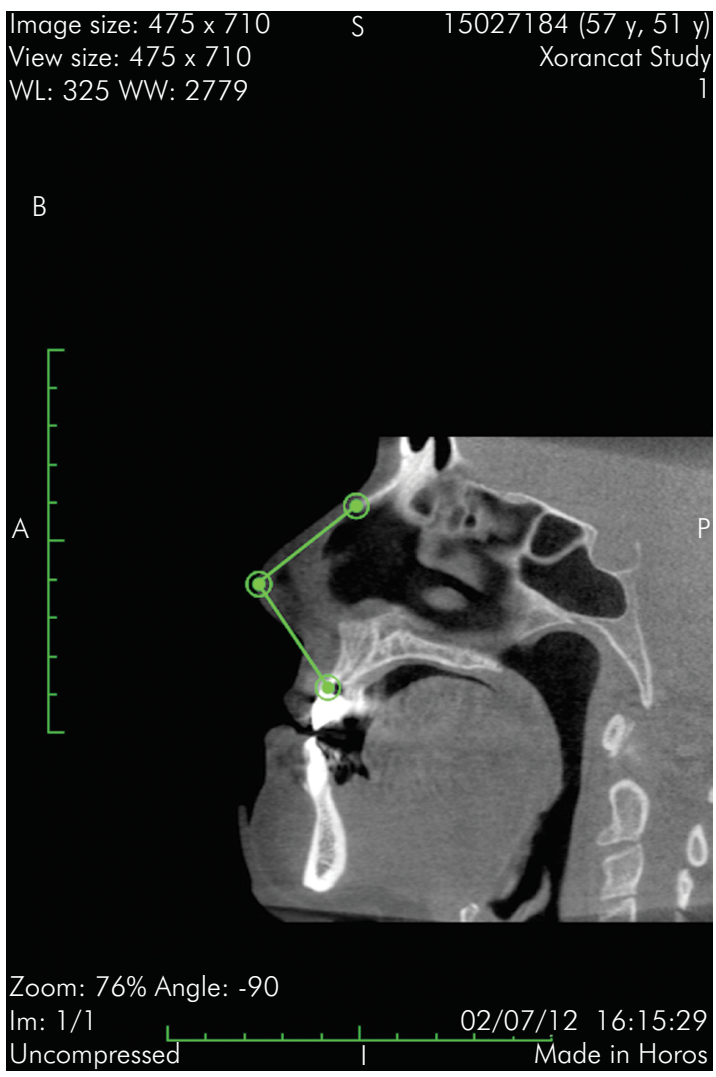

Figure 2. Sagittal window of multiplanar reconstruction with $0 \mathrm{~mm}$ MIP set, medial sagittal cut. The lines establish the actual angle.

estimated distances (actual pn - estimated pn). The same test was used to analyze whether there was a difference in the mean actual angle for the male and the female groups.

\section{Results}

A single examiner obtained the required measurements. The result of the intraclass correlation coefficient (ICC) test showed high intraexaminer agreement (ICC: 0.99).

The mean age of the female $(n=171)$ and male $(\mathrm{n}=57)$ groups was similar (51.9 and 51.2, respectively), but the variation in age range was higher in the female (24-86 years) than in the male group (24-73 years).

The mean angle studied was $96.5^{\circ}( \pm 4.1)$ for the entire sample, $(n=228)$, considering a range from $78^{\circ}$ to $100^{\circ}$. The female group presented a higher 


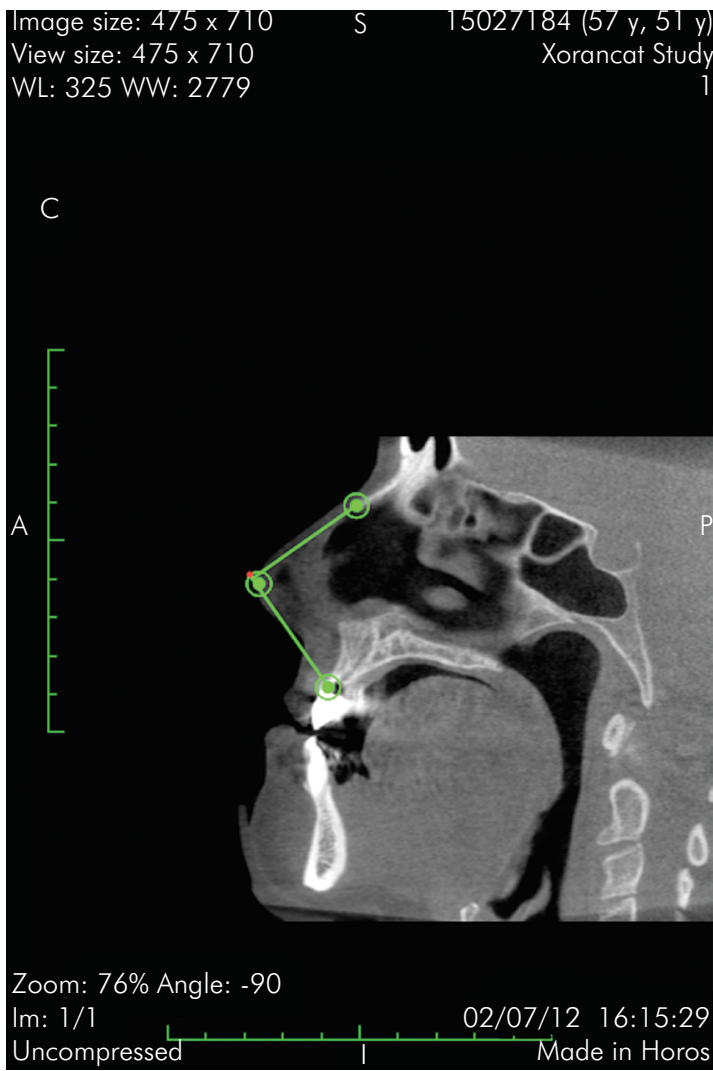

Figure 3. Sagittal window of multiplanar reconstruction with $0 \mathrm{~mm}$ MIP set, medial sagittal cut. The lines establish the estimated angle.

mean of $97.1^{\circ}( \pm 3.4)\left(\right.$ range of $83^{\circ}$ to $\left.100^{\circ}\right)$, whereas the male group had a mean angle of $94.5^{\circ}( \pm 5.3)$, with a greater range than the female group $\left(78^{\circ}\right.$ to $\left.100^{\circ}\right)$. Table 1 shows the distribution of the mean rhi-pn-pr angle, according to each age group. Note that most of the female subjects $(n=71)$ were at an age level in which the mean rhi-pn-pr angle is greater than $90^{\circ}$. In the male group, there were more individuals $(n=20)$ in the age group that has a mean angle close to $90^{\circ}$ (level 4).

The distance between the actual and estimated pn points was measured and resulted in $2.7( \pm 1.4)$ $\mathrm{mm}$ for the female group and $1.7 \mathrm{~mm}( \pm 2.1)$ for the male group. Finally, this analysis showed that the distance between the actual and estimated pn points obtained by direct measurement was different from that obtained according to the hypothesis that each $1^{\mathrm{o}}$ of difference in the rhi-pn-pr angle is equivalent to $0.31 \mathrm{~mm}$ (Table 2). The same diverging result was
Table 1. Mean (DP) rhi-pn-pr angle, according to age range for female and male groups.

\begin{tabular}{lcc}
\hline Variable & $\mathrm{n}$ & Mean angle $\left(^{\circ}\right)$ \\
\hline $\begin{array}{c}\text { Female group } \\
\text { Level 1 }\end{array}$ & 171 & \\
Level 2 & 37 & $98.4( \pm 1.4)$ \\
Level 3 & 51 & $97.2( \pm 3.4)$ \\
Level 4 & 71 & $96.6( \pm 4.0)$ \\
Male group & 57 & \\
Level 1 & 7 & $96.4( \pm 4.4)$ \\
Level 2 & 14 & $96.8( \pm 3.7)$ \\
Level 3 & 16 & $92.2( \pm 6.3)$ \\
Level 4 & 20 & $94.2( \pm 5.1)$ \\
\hline
\end{tabular}

Level 1: 24 to 33.9 years; Level 2: 34 to 43.9 years; Level 3: 44 to 53.9 years; Level 4 : over 54 years of age.

observed when considering each group of individuals according to sex.

\section{Discussion}

There are few studies in the forensic literature on facial reconstruction that use Brazilian samples, thus making it difficult to establish reliable parameters for facial approximation in this population. The sample described herein was composed only of Brazilian individuals. In addition, the present study used a sample of cone-beam CT images instead of lateral radiographies. Cone-beam CT images feature better dimensional stability than radiographies, thus making the results of the present study potentially more reliable.

Facial recognition does not depend only on the accuracy of the reconstruction. ${ }^{2,3}$ Notably, the research in this area conducted by other studies has contributed toward increasing the accuracy level of these sculptures, thus promoting better recognition rates in a forensic context. ${ }^{1}$ Therefore, it is important to establish a standard and reproducible method for estimating each facial feature. TedeschiOliveira et al. ${ }^{24}$ proposed a method to estimate the location of the nasal tip, validated by the present study.

As in their pioneer research, the present study found a higher average angular vertex (rhi-pn-pr) for women than men. The mean angle studied was higher than $90^{\circ}$ 
Table 2. Difference between actual and estimated distances of actual and estimated pn points.

\begin{tabular}{lcccccc}
\hline Variable & T value & $p$-value & T value** & $p$-value* & T value** & $p$-value ${ }^{* * *}$ \\
\hline Actual distance & 21.5 & $<0.001$ & 24.2 & $<0.001$ & 5.8 & $<0.001$ \\
Estimated distance & 23.4 & $<0.001$ & 26.6 & $<0.001$ & 6.4 & $<0.001$ \\
\hline
\end{tabular}

${ }^{*}$ whole sample $(\mathrm{n}=228) ;{ }^{* *}$ female group $(\mathrm{n}=171) ;{ }^{* * *}$ male group $(\mathrm{n}=57)$.

in the female group. However, the inaccuracy of the nose tip location, considering a $90^{\circ}$ angle, was off by only $2.7 \mathrm{~mm}( \pm 1.4)$. This difference was smaller in the male group ( $1.7 \mathrm{~mm} \pm 2.1)$, corroborating the findings of Tedeschi-Oliveira et al. ${ }^{24}$ The estimated nose tip was placed about $3 \mathrm{~mm}$ from the actual pronasale point, a difference too small to compromise the facial set, thereby resulting in successful recognition. The angle in question was also analyzed, considering stratification of the sample by age group. Considering both sexes, the angle ranged from $92^{\circ}$ to $98^{\circ}$, corroborating previous findings ${ }^{24}$ that the value of the angle is about $90^{\circ}$.

The literature points out that nose size increases as age progresses. ${ }^{7}$ Sforza et al. ${ }^{7}$ observed that age influenced the volume, area, linear distances, proportions and nose angle of their studied sample. Almost all parameters analyzed in their study increased with advancing age, except the angle of the nose tip (formed by the junction of the nasal, pronasale and subnasale points). This decreased with increasing age, indicating that the nasal tip turns down over one's lifetime.

The age of the present study sample ranged from 24 to 86 years for the female group and from 24 to 73 years for the male group. However, the angle did not vary significantly across the different age levels, but maintained its distribution frequency of about $90^{\circ}$. The same was reported in the study by TedeschiOliveira et al. ${ }^{24}$ Thus, the method proposed by these authors can be applied to adult skulls, regardless of the estimated age.
The sample of this study, like that of TedeschiOliveira et al. ${ }^{24}$ was composed of individuals from the southwestern region of Brazil. Since Brazil has a very mixed population, the Tedeschi-Oliveira technique should be validated in other Brazilian regions, in order to confirm the results in a population with ethnical characteristics potentially distinct from those of the southwestern sample.

Finally, the present study tested the hypothesis that each $1^{\circ}$ of difference between the actual and estimated rhi-pn-pr angle (considering the $90^{\circ}$ value) represents $0.31 \mathrm{~mm}$ of deviation between the actual and the estimated pn points. ${ }^{24}$ However, these findings do not corroborate the hypothesis put forward by the Tedeschi-Oliveira study.

\section{Conclusion}

This study validated the technique presented by Tedeschi-Oliveira et al., ${ }^{24}$ and established its applicability to a Brazilian sample, with minimum variation. The results prove that a reliable nasal tip may be sculpted using the proposed $90^{\circ}$ method.

\section{Acknowledgments}

The authors are grateful to LAPI FO-USP for providing their collection of cone beam CT images, to MSc. Alexandre Baumgarten for conducting the statistical analysis, and to CAPES for its financial support (Funding code: 001).

\section{References}

1. Wilkinson C. Forensic facial reconstruction. New York: Cambridge University Press; 2004. https://doi.org/10.1017/CBO9781107340961.

2. Ellis HD, Shepherd JW, Davies GM. Identification of familiar and unfamiliar faces from internal and external features: some implications for theories of face recognition. Perception. 1979;8(4):431-9. https://doi.org/10.1068/p080431

3. Davy-Jow S. The devil is in the details: a synthesis of psychology of facial perception and its applications in forensic facial reconstruction. Sci Justice. 2013 Jun;53(2):230-5. https://doi.org/10.1016/i.scijus.2013.01.004 
Facial reconstruction: validation of the Tedeschi-Oliveira method for estimating the pronasale point in Brazilians

4. Enlow DH, Hans MG. Essentials of facial growth. 2nd ed. Philadelphia: W.B. Saunders; 1996.

5. Farkas LG. Anthropometry of the head and face. 2nd ed. New York: Raven Press; 1994.

6. Chen F, Chen Y, Yu Y, Qiang Y, Liu M, Fulton D, et al. Age and sex related measurement of craniofacial soft tissue thickness and nasal profile in the Chinese population. Forensic Sci Int. 2011 Oct;212(1-3):272.e1-6. https://doi.org/10.1016/i.forsciint.2011.05.027

7. Sforza C, Grandi G, De Menezes M, Tartaglia GM, Ferrario VF. Age- and sex-related changes in the normal human external nose. Forensic Sci Int. 2011 Jan;204(1-3):205.e1-9. https://doi.org/10.1016/i.forsciint.2010.07.027

8. Chopard RP. Anatomia odontológica e topográfica da cabeça e do pescoço. São Paulo: Santos; 2012.

9. Norton NS. Netter Atlas da cabeça e pescoço. Rio de Janeiro: Elsevier; 2007.

10. Costa J, Prates JC, Castilho HT, Santos RA. Craniometric study of nasal bones and frontal process of maxila. Int J Morphol. 2005;23(1):9-12. https://doi.org/10.4067/S0717-95022005000100002

11. Anderson KJ, Henneberg M, Norris RM. Anatomy of the nasal profile. J Anat. 2008 Aug;213(2):210-6. https://doi.org/10.1111/j.1469-7580.2008.00924.x

12. Macho GA. An appraisal of plastic reconstruction of the external nose. J Forensic Sci. 1986 Oct;31(4):1391-403. https://doi.org/10.1520/JFS11917J

13. Hoffman BE, McConathy DA, Coward M, Saddler L. Relationship between the piriform aperture and interalar nasal widths in adult males. J Forensic Sci. 1991 Jul;36(4):1152-61. https://doi.org/10.1520/JFS13130J

14. Prokopec M, Ubelaker DH. Reconstructing the shape of the nose according to the skull. Forensic Science Communications. 2002 Jan; $4(1)$.

15. Stephan CN, Henneberg M, Sampson W. Predicting nose projection and pronasale position in facial approximation: a test of published methods and proposal of new guidelines. Am J Phys Anthropol. 2003 Nov;122(3):240-50. https://doi.org/10.1002/aipa.10300

16. Rynn C, Wilkinson C. Appraisal of traditional and recently proposed relationships between the hard and soft dimension of the nose in profile. Am J Phys Anthropol. 2006 Jul;130(3):364-73. https://doi.org/10.1002/ajpa.20337

17. Rynn C, Wilkinson CM, Peters HL. Prediction of nasal morphology from the skull. Forensic Sci Med Pathol. 2010 Mar;6(1):20-34. https://doi.org/10.1007/s12024-009-9124-6

18. Ullrich $\mathrm{H}$, Stephan $\mathrm{CN}$. On Gerasimov's plastic facial reconstruction technique: new insights to facilitate repeatability. J Forensic Sci. 2011 Mar;56(2):470-4. https://doi.org/10.1111/j.1556-4029.2010.01672.x

19. Davy-Jow SL, Decker SJ, Ford JM. A simple method of nose tip shape validation for facial approximation. Forensic Sci Int. 2012 Jan;214(1-3):208.el-3. https://doi.org/10.1016/i.forsciint.2011.07.039

20. Mala PZ. Pronasale position: an appraisal of two recently proposed methods for predicting nasal projection in facial reconstruction. J Forensic Sci. 2013 Jul;58(4):957-63. https://doi.org/10.1111/1556-4029.12128

21. Lee KM, Lee WJ, Cho JH, Hwang HS. Three-dimensional prediction of the nose for facial reconstruction using cone-beam computed tomography. Forensic Sci Int. 2014 Mar;236:194.el-5. https://doi.org/10.1016/i.forsciint.2013.12.035 PMID:24486159

22. Lapointe GM, Lynnerup N, Hoppa RD. Validation of the new interpretation of Gerasimov's nasal projection method for forensic facial approximation using CT data. J Forensic Sci. 2016 Jan;61 Suppl 1:S193-200. https://doi.org/10.1111/1556-4029.12920

23. Utsuno H, Kageyama T, Uchida K, Kibayashi K, Sakurada K, Uemura K. Pilot study to establish a nasal tip prediction method from unknown human skeletal remains for facial reconstruction and skull photo superimposition as applied to a Japanese male populations. J Forensic Leg Med. 2016 Feb;38:75-80. https://doi.org/10.1016/i.flm.2015.11.017

24. Tedeschi-Oliveira SV, Beaini TL, Melani RF. Forensic facial reconstruction: nasal projection in Brazilian adults. Forensic Sci Int. 2016 Sep;266:123-9. https://doi.org/10.1016/j.forsciint.2016.05.004 